\title{
2. C.banding Patterns in Somatic and Meiotic Chromosomes of Crepis capillaris
}

\author{
By Ryuso TANAKa and Hiroko Komatsu \\ Botanical Institute, Faculty of Science, \\ Hiroshima University, Hiroshima 730 \\ (Communicated by Sajiro Makino, M. J. A., April 12, 1977)
}

Much has been known about the C-banding patterns of somatic and meiotic chromosomes in both animals and plants (Polani 1972, Forejt 1973, Dret and Stoll 1974, Marks 1974, Schmid and Krone 1976), but a question has remained as to whether, or not, the same patterns appear constantly at the particular region of the chromosomes in various types of somatic and meiotic cells. In many reported cases, some difficulties occur for the identification of meiotic chromosomes. The situation has led us to undertake a comparative study of the C-banding pattern in three different types of cells of Crepis capillaris, since the latter possesses a very low chromosome number $(2 n=6)$, and individual chromosomes are identifiable with easiness.

Preparation. Crepis capillaris $(2 n=6)$ was supplied through the courtesy of Prof. Y. Shimizu, Tohoku University, to whom we are grateful. Root tip cells, young leaf cells of shoot apex and pollen mother cells (PMCs) of young flower bud provided materials for this study. According to Tanaka and Taniguchi (1975), the materials were treated as follows: root tips and young leaves were pretreated with $0.002 \mathrm{M}$-hydroxyquinoline at $18-20^{\circ} \mathrm{C}$ for $2.5 \mathrm{hr}$. Root tips were fixed with ethanol + acetic acid $(3: 1)$ at $5^{\circ} \mathrm{C}$ for $24 \mathrm{hr}$. Young leaves were fixed with ethanol + acetic acid + chloroform $(2: 1: 1)$. Both the root tips and young leaves were hydrolysed with $1 \mathrm{~N}-\mathrm{HCl}+45 \%$ acetic acid $(2: 1)$ at $60^{\circ} \mathrm{C}$ for $15 \mathrm{sec}$. and rinsed in deionized water for 10 $30 \mathrm{~min}$. They were squashed in a drop of $45 \%$ acetic acid under the coverslip. Flower buds were fixed with ethanol + acetic acid + chloroform $(2: 1: 1)$. PMCs were taken from the anther in fixed flower bud and squashed under the coverslip. After coverslips were removed with dry ice, the slides were air-dried for 12-24 hr., incubated in 5\% aqueous solution of barium hydroxide at $50^{\circ} \mathrm{C}$ for $5 \mathrm{~min}$., and rinsed in deionized water for $10-20 \mathrm{~min}$. They were incubated in $2 \times \mathrm{SSC}$ $\left(0.3 \mathrm{M} \mathrm{NaCl}\right.$ and $0.003 \mathrm{M} \mathrm{C}_{6} \mathrm{H}_{5} \mathrm{Na}_{3} \mathrm{O}_{7} \cdot 2 \mathrm{H}_{2} \mathrm{O}$ in deionized water $)$ at $60^{\circ} \mathrm{C}$ for $2 \mathrm{hr}$. and rinsed in deionized water for 10-30 min. They were stained with a buffered Giemsa solution (1.5\%, Merk) at 18$20^{\circ} \mathrm{C}$ for $15 \mathrm{~min}$. Finally the preparations were rinsed in deionized 
water, and air-dried for $24 \mathrm{hr}$., soaked in xylene and mounted in Eukitt (Kindler Co.). Following the above treatments, the bands demonstrated were identified as the C-bands after Taniguchi et al. (1975).

Results. 1) Somatic chromosomes of root tip cells. In chromosome pair 1 three bands were demonstrated: two medium-sized bands on the short arm and a small band on the distal region of the long arm (Fig. 1A). While in most cells the medium-sized bands appeared in parallel arrangement, in some cells they occurred as one large band. The two bands of the short arm made their appearance in 21 cells so far examined. The incidence in appearance of the small band on the long arm was very few $(17 \%)$.

In chromosome pair 2 , five bands were apparent: a medium-sized

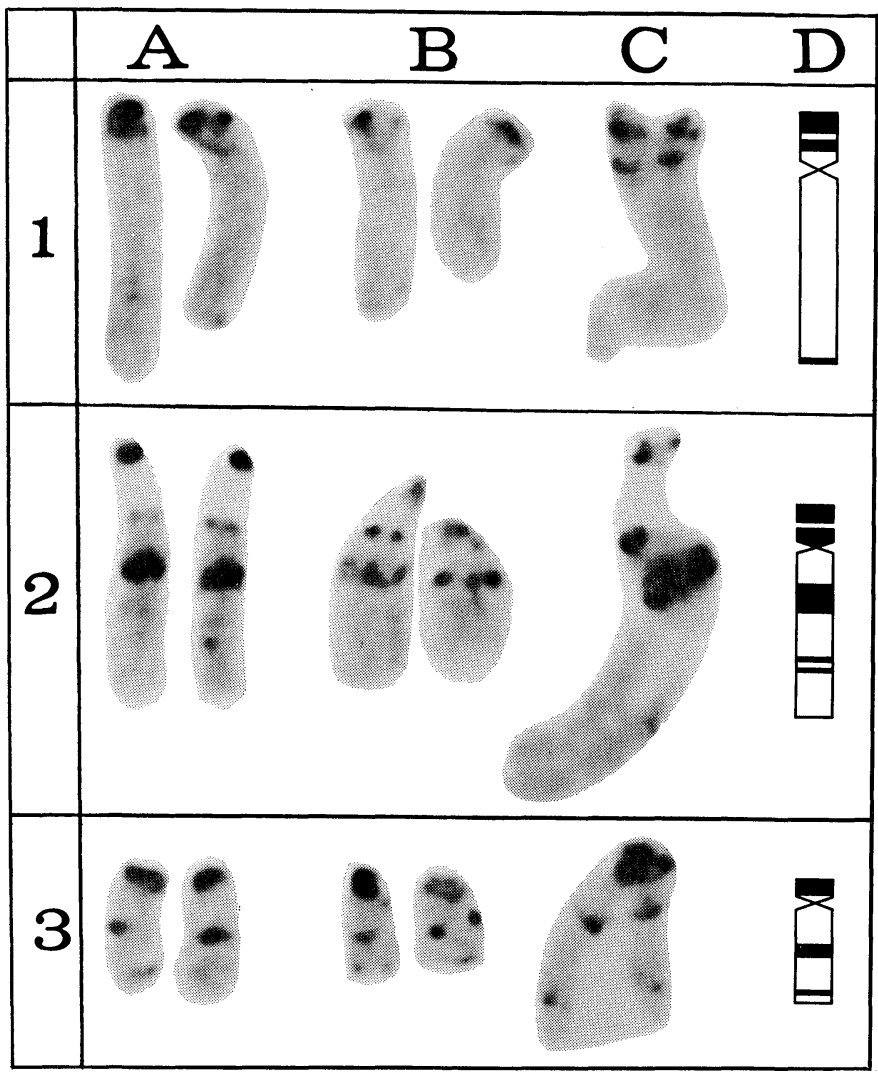

Fig. 1. C-bandings in the chromosomes 1,2 and 3 of Crepis capillaris. A, root tip chromosomes at metaphase. B, somatic young leaf chromosomes at metaphase. $\mathrm{C}$, meiotic chromosomes at diakinesis in a pollen mother cell. D, schematically represented C-banding patterns. $\times 3300$. 
band on the whole region of the satellite, a medium-sized band on the whole region of the satellite, a medium-sized band on the proximal whole region of the short arm, a large band on the proximal interstitial region of the long arm, and two small bands on the distal interstitial region of the long arm (Fig. 1A). All the cells examined showed these bands except for the two small bands which occurred only in $3 \%$ of the cells. One of the latter was observed in $42 \%$ of the cells.

In chromosome pair 3, three bands were observed: a large band which covered the whole distal and interstitial regions of the short arm, a medium-sized band on the central interstitial region of the long arm, and a small band on the distal region of the long arm (Fig. 1A). The former two appeared in all the cells examined, while the latter was observable in about one half of the cells.

2) Somatic chromosomes of young leaf cells. The meristematic cells of young leaves showed the banding patterns in all the chromosome pairs 1, 2 and 3 (Fig. 1B). They were of similar nature to those of root tip cells in size, location and frequency.

3) Meiotic chromosomes of PMCs. At meiosis I, all bivalents examined in the PMCs showed bands. At pachytene the bands appeared as several fused blocks in the paired chromosomes. At diakinesis and metaphase I the bands were seen as follows:

In each homologue of chromosomes 1 two medium-sized bands occurred arranging parallel on the terminal region of the short arm (Fig. 1C). On the distal region of the long arm, a small band appeared though not constantly.

Each homologue of chromosomes 2 showed two medium-sized bands on the satellite and the proximal region of the short arm, a large band on the proximal interstitial region of the long arm, and a small band on the distal interstitial region of the long arm (Fig. 1C), though the latter was not constant in appearance.

Each of the homologue of chromosomes 3 had three bands: one large band occurring on the short arm of each chromosome, one medium-sized band on the central interstitial region of the long arm of each, and one small band localized on the distal region of the long arm of each (Fig. 1C). The latter was not constant.

All metaphase I chromosomes so far examined showed chiasmata in both the banded and the non-banded regions. A similar feature was reported in the mouse (Polani 1972).

The banding patterns of chromosomes found in three different types of cells are shown in Fig. 1, in which the chromosomes of a complement were arranged on ordinate, and those from the different cells on abscissa. It was shown that the chromosomes from the dif- 
ferent cells were characterized by C-bands of similar banding patterns. Fig. $1 \mathrm{D}$ is a schematical representation of the bands. The occurrence of the large and medium-sized bands was constant in both the somatic and meiotic cells, whereas the small bands were not always constant in appearance.

Acknowledgements. Our gratitude is expressed to Emeritus Professor Sajiro Makino, M. J.A., for his revision. The work was supported by grants from the Ministry of Education, Japan.

\section{References}

Dret, M. E., and M. Stoll: Chromosoma (Berl.), 48, 367-390 (1974).

Forejt, J.: Chromosoma (Berl.), 43, 187-201 (1973).

Marks, G. E.: Chromosoma (Berl.), 49, 113-119 (1974).

Polani, P. E.: Chromosoma (Berl.), 36, 343-374 (1972).

Schmid, M., and W. Krone: Chromosoma (Berl.), 56, 327-347 (1976).

Tanaka, R., and K. Taniguchi: Jap. J. Genetics, 50, 163-167 (1975).

Taniguchi, K., R. Tanaka, Y. Yonezawa, and H. Komatsu: La Kromosomo, 100, 3123-3135 (1975) (in Japanese). 